\title{
ADDITION TO THE VOL. 21 NO. 1 TABLE OF CONTENTS
}

The cover table of contents for Volume 21 Number 1 is missing an entry. It should include the following:

A. Maliszewski

On the Differences of Darboux Upper Semicontinuous

Functions . . . . . . . . . . . . . . . . . . . . . . . 258

The editors apologize for the omission.

Received by the editors January 1, 2013

Communicated by: Paul D. Humke 
